\title{
A Syntactic Account for the Power of Verbs within X-Phemism: A Corpus-Base Exploration
}

\author{
Maather Mohammad Al-Rawi ${ }^{1} \&$ Nuha Suleiman Daoud Al-Shurafa ${ }^{1}$ \\ ${ }^{1}$ Department of European Languages, Faculty of Arts and Humanities, King Abdul-Aziz University, Jeddah, \\ Saudi Arabia \\ Correspondence: Maather Mohammad Al-Rawi, Assistant Professor of theoretical Linguistics, Department of \\ European Languages, Faculty of Arts and Humanities, King Abdul-Aziz University, Jeddah, Saudi Arabia. Tel: \\ 050-467-8975. E-mail: mmalrawi@kau.edu.sa
}

Correspondence: Nuha Suleiman Daoud Al-Shurafa, Professor of theoretical Linguistics, Department of European languages, Faculty of Arts and Humanities, King Abdul-Aziz University, Jeddah, Saudi Arabia. Tel: 0503-009-004. E-mail: nalshurafa@kau.edu.sa

Received: January 15, 2016 Accepted: April 29, 2016 Online Published: May 15, 2016

doi: 10.5539/elt.v9n7p87 URL: http://dx.doi.org/10.5539/elt.v9n7p87

\begin{abstract}
The main aim of this paper is to examine the syntactic status of a selected text-corpus focus, with a special focus on the verb within its Verb-Phrase. The major claim is that the power of the verb in its VP is loaded syntactically through which the speaker's desire of the doublespeak within X-Phemism is achieved. In order to fulfill this claim, a corpus-based exploration is applied on the selected data produced in Standard English. The analysis is accounted for a conceptualization of grammar that is based on general syntactic constraints on a well-formedness. The syntactic conceptualization (Chomsky, 2000; Ouhalla, 2002) is selected in its broad sense, as the basic framework where it best captures the syntactic role played by the verb-predicate and its various arguments.
\end{abstract}

Keywords: X-phemism, doublespeak, power of verbs, inflated-loaded language, circumlocuted-roundabout verbs

\section{Introduction}

\subsection{X-Phemism, Doublespeak, and Power of Words}

The theory of X-phemism perspectives has witnessed a remarkable progress in the past three decades or so, (Bolinger, 1980), and is now one of the main attractive areas of academic research. Partly, perhaps, because of the pioneering works of some scholars such as Lutz (1989 and 1996) who has defined doublespeak, which is related to euphemism, as "language that only pretends to communicate, that makes the bad seems good, the unpleasant attractive or at least tolerable" (p. 17). He has classified four kinds of doublespeak, as: euphemism, jargon, inflated language and bureaucratese (or gobbledygook). The four types of X-phemism are related to the term 'Power Word' in that a selected word in one certain context can denote a number of other meanings to influence and attract the listener.

The inspiration for the term 'doublespeak' came from "doublethink" and "new speaker" of George Orwell's Nineteen Eighty-Four, a novel that showed how language can be used as an instrument "for concealing or preventing thought", (Orwell, 1950, p. 11). However, extended researches reveal more functions of those terms and exceed the relation to Orwell's novel, (Al-Hamad \& Salman, 2012; Allan, 2009; Allan \& Burridge, 1991 \& 2006; Aunk, 2009; Bolinger, 1980; Bakhtiar, 2012; Bourdieu, 1981; Enright, 1985; Fernandez 2008; Galal, 2014; Gladney et al., 2005; Khanfar, 2012; Khatabi, 2009; Kick, 2001; Mazid, 20032004 \& 2007a\&b; McGlone, Matthew, Beck, Gary, \& Abigail, 2006; Qadhi, 2009; and Reznikove, 2001).

\subsection{The Main Aim}

In this paper, we will present an account of the relation between the verbal elements structure of the speaker's choices to create doublespeak. The head-verb, which is considered as the strongest structural element in the sentence (Ouhalla, 2002), is the loaded word with the required power, achieves the speaker's intended meaning. Our gathered data are good example where the power of verbs is revealed because it is produced by an educated bilingual Arab with a good mastery of English. 
The power of words refers to the effect of verbs which the speaker selects to convey to the addressee certain highlighted concepts. Accordingly, a structural classification is applied on the verbs after they are selected from the corpus-data. Moreover, their X-phemistic role is analyzed following Lutz classification of the four main types as mentioned above.

This seems to provide a worthy enterprise, because whilst there is a substantial body of research on the conceptual metaphor theory of the euphemistic or dysphemistic devices, (Al-Barakati, 2009; Aunk, 2009; Bolinger, 1980; Fernandez, 2008; Khatabi, 2009; Kick, 2009; Mazid, 2007a, 2007b, and 2008). To the best of the author's knowledge, little or no attention has been devoted to the syntactic analysis of power of the verbs within $\mathrm{X}$-phemism.

With this in view, and granted that the power of verbs within X-phemism is highly dependent on words, this research study is not based on isolated words, but rather, on a coherent and a contextualized discourse. A structural mechanism account of the frequency of the head-verb (henceforth HV), and the clustering constituents is provided, restricting the discussion to the euphemistic types of doublespeak. We will argue that the verb enjoys a syntactic power besides its meaning which extends to its arguments to fulfill the speaker's desire.

\section{Describe Relevant Scholarship}

\subsection{Definition of Terms and Types of X-Phemism}

Terms and types of X-phemism are briefly defined with reference to the dictionaries by Holder (2003) and Rawson (1995). A diagram which has been developed for the purpose of this study is then presented.

2.1.1 Euphemism: is the first type in X-phemism, according to Lutz (1996). It is a mild word or expression that is overtly polite, sweet sounding, evasive or vague for offensive thought.

2.1.2 Jargon: is the second type of Lutz classification. It is the language of specific activity, profession or group, which can be understood by those who belong to the same group or community. It consists of the following three sub-types in (2.2.a), (2.2.b) and (2.2.c) below:

2.1.2.1 Technical Terms: refer to certain in-groups to facilitate communication where it is hindered with the out-group.

2.1.2.2. Slogan: is another sub-type of Jargon that is precise and concise and refers to a brief message that crystallizes and defines the idea.

2.1.2.3 Emotive Words: are loaded words or phrases with strong emotions. If the connotation is evoked negatively, they are called "sneer" words. The opposite is "purr" words loaded with positive connotation.

2.1.3 Gobbledygook (or bureaucratese): is the third type according to Lutz. It refers to sheer volume of words or complicated language that makes it sound like something is being said when nothing is really being said at all. It is designed to confuse the audience.

2.1.4 Inflated (or pompous) Language: is the fourth and last type of Lutz division and is the use of words or phrases to make something feel more important than it really is. Its sub-types are: Description of Words and Indirection (Circumlocution or roundabout) Language.

2.1.5 Dysphemism (or Malphemism): is the opposite pole of Euphemism where harsh, blunt or offensive expression is used. It also refers to humorously deprecating usages.

Other terms associate to X-phemism are coined by Allan and Burridge (2006). They are included below and are useful to the analysis in this paper.

2.1.6 Orthophesm: are terms of straight talk and natural expressions, like words of the day and neutral names.

2.1.7 Cocophemism: is usually deliberately offensive.

2.1.8 Pejorative: is an expression with negative effect, like the words 'punk' and 'gay'.

2.1.9 Hyperbole: is similar in sense to the above-mentioned inflated language.

2.1.10 Power Words: in Loaded Language influence the listener through emotions, e.g. the use of 'regime' versus 'government'; and 'elitist' versus 'expert'.

The paper refers to the above four types where they are visually presented on the following diagram developed for the purpose of this paper. 


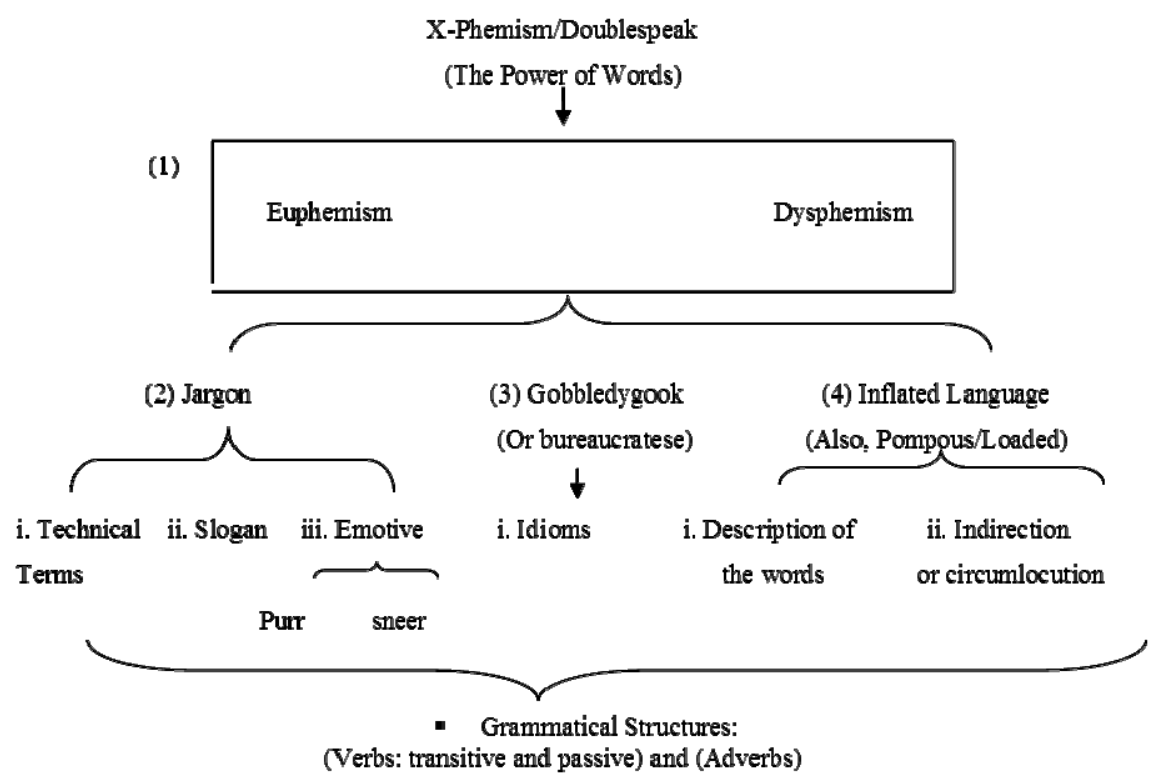

Figure (1): X-Phemism types and sub-types as developed for the purpose of this study

\section{Theoretical Framework}

The description of doublespeak lies within the theoretical framework of syntactic structural analysis in its broadest sense, (Chomsky, 2000; Ouhalla, 2002) by casting attention on the syntactic mechanisms of the speaker's lexical choice of verbs such as transitive and passive among other choices. These structural choices are found to have a considerable role to play in the creation of meaning within the context of X-phemism.

According to the new model of syntax, syntactic derivations are manipulations of relevant lexical choices governed by specific principles (Roger, Michael, \& Uriajereka, 2002). These lexical choices are numerations at the logical form where the deep structure is created for conceptual reasons, (Ouhalla, 2002). Within this frame, the verb creates an event where its involved participant(s) is/are the argument(s). The theoretical program helps to account for the verbal syntactic role with relation to X-phemism devices to capture the related characteristics.

\section{Related Literature}

Following extensive review of the related literature, it is apparent that the more detailed studies on X-phemism and its various perspectives have taken place relatively recently. With reference to the discussion of the critical discourse theory and to pragmatics, prominent contributions are noteworthy. Allan's (2009) discuses the connotations of English colour terms based on X-phemism. Earlier, Allan and Burridge (1991) discuss euphemism and dysphemism language used as shield and weapon. They discuss later (Allan and Burridge, 2006) taboo words and the censoring of language and Lutz (1996) defines four types of X-phemism.

Power as one important concept to this field has been discussed by the prominent scholar Van Dijk in a number of published works as that in (2007). His latest work (Van Dijk, 2010) discusses the relationship between discourse and context within the sociological approach where power and society involve positive and negative aspects where they relate to X-phemism.

Gladney, Albert and Rittenberg (2005) discuss a euphemistic text which has relations to affecting attitude and behavior. The question of 'How does euphemism work in the mind?' has been recommended for future work. Grice's (1989) theory of meaning explicates the dynamic effect of words and their meanings as a helpful tool in a conversation. All the above topics relate to this paper within the interdisciplinary field of theory of speech and conversation.

Many Arab linguists contributed mostly in English to discuss X-phemism from various aspects which prove value to the background of our work. Mazid, (2003), (2004) and (2007a), studies ideology and control in a selected speech and newspaper, X-phemism in war on Iraqi discourse. He also applies power, culture, ideology and X-phemism in translation between English and Arabic. His work in 2008 discusses the cartoons of former 
President George W. Bush and Osama Ben Laden, and in 2009 he analyzes one fable extracted from the fables' book of Kaleela and Dimna (Wood, 2008) where language and power are the main theme of discussion. He has a sizable share of all Arab contributors. His conclusions allude to our study.

Other Arab contributors are: Qadhi (2009) with a sociolinguistic comparison of euphemism in Arabic and English. In 1995, Farghal discusses euphemism and Grice approach of the word power; and in 2005 he discusses Arabic euphemism in English translation. Moreover, Galal (2014) determines two domains for euphemism and metaphors: the "source domain" and the "target domain" (pp. 154-155). He finds that both English and Arabic use ten strikingly similar complex conceptual metaphors to lessen the influence of death. Al-Hamad and Salman (2013) show that the holy Qur'an tends to commonly emphasize topics such as sickness, divorce and death among others by replacing words relating to these topics with less directness to avoid embarrassment. Earlier, Khanfar (2012) studied euphemism in Arabic typology and refers to euphemism which comes from Greek and is used to avoid speaking loudly about religious matters. In 2012, Bakhtiar also claims that any linguistic expression must have three principles to function as euphemism: distance principle, correlation principle and pleasantness principle. He also adds that ambiguity is a crucial feature and permits mitigation of taboo area.

The methodology, discussion, analysis and conclusions of the above works prove congruent to the theme of this paper.

\section{The Data Collection, Analysis \& Discussion}

\subsection{The Data and the Subjects}

The data is originally produced in Standard English by Queen Rania Abdullah of Jordan, who is a well educated Arab bilingual of Palestinian origin. The fifteen minutes' interview by Opera Winfrey has been announced on the T.V English Channel of the MBC on 5th October, 2005, when queen Rania was back then 31years of age.

The text is unique. It is produced by a candidate with a rich social, linguistic, religious and Political-Middle Eastern background, where those fields contribute to create wealthy topics of this interview. The author believes that the range of the context is relatively wide and is a rich sample to analyze for X-phemism. The size of the selected text also conforms to the papers limitation.

The interview consists of 1273 words where the interviewer's speech has been excluded. The verbs count to 368 of the total words. The verb frequency amounts to $29 \%$ of the overall data.

\subsection{Discussion and Results}

The selected corpus-data goes through a process of filtering the verbs and classifying their syntactic structure for the purpose of analyzing which structural form has been used most, least and in the middle. This step helps to assess evaluating the interrelation between structure and the meaning it coveys. A conceptualization of the four $\mathrm{X}$-phemism types follows, by applying each device on the extracted verbs. Consequently, the subsequent outcome of the power verb structure is revealed.

\subsubsection{The Corpus-Data}

The conversation in the interview is well handled by the one candidate, Queen Rania Abdullah of Jordan. Her speech approximates 67 lines that count approximately 1273 words. The vast majority of sentence type in the data is the complex-complex or complex-compound with transitive predicates which require one or more arguments. Those verbs are mainly dynamic and carry the sense of motion with positive or negative connotation. Some verbs are lexicalized and others participate in creating the required inflated language.

The speech in general is euphemized with no trace of dysphemism. The speech deals with vital issues such as Arab women and their right in Islam, honor killing in Jordan, radical Muslims and the reaction of the queen and the Arabs in general towards the 9/11 attack on America.

\subsubsection{Verbs as Power Words and Their VPs Classification in the Corpus-Data}

The whole speech of Queen Rania is euphemized where firm ideas are basically introduced through six verbal devises. These are classified as: coordinated HVs; infinitival-verbs following HVs; frequent usage of adverbs inside VPs; lexicalized verbs; verbs in the passive voice; and dynamic HVs which refer to motion and the five human-senses in vast majority. These devices of verbs and VPs are the basic elements to participate in producing a euphemized mild style.

The occurrence of verbs in their six structural devices form $29 \%$ that is 368 verbs, among the total number of words which is 1273 words in the whole interview, (see sub-section 5.1 above). A visual presentation is useful to present the summary of these indications in the graph below: 


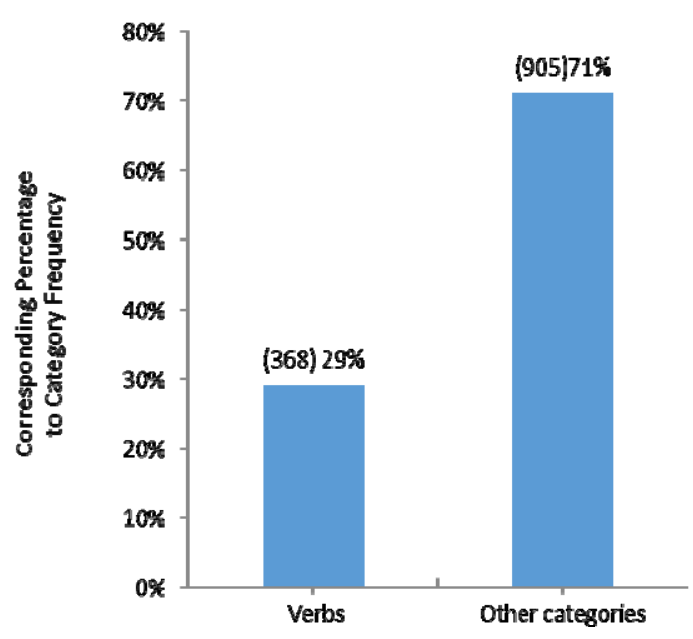

Graph 1. Verbs and other categories in the data: frequencies and corresponding percentages

The presentation below includes citations extracted from the data, of the six-verbal structures which are found to have a significant role to play in euphemizing the style.

Firstly, the use of HV followed by infinitival verb-structure as in:

(1) I [HV think] for the past couple of weeks, we've all been [HV trying [IfnVP to understand]] it; [HV trying [InfVP to make]] sense of it.

The HV of the whole clause above is [HV think]. It is followed by two HVs in the subordinate clause which are then followed by two successive infinitives as: [HV trying [InfVP to understand]] and [HV trying [InfVP to make]]. This verbal-structure in the above complex-complex sentence helps to convey a euphemized sense expressed by the speaker. The verbal-structure also helps to express the shared attitude of distress and rejection of the violent attack to which the topic of the sentence referrers.

This device occupies the vast majority among the rest of verbal-devices in the corpus-data. It has the frequency of 108 usages which is equivalent to $29.4 \%$ of the total verb structure devices.

Secondly, the use of adverbs that penetrates through their VP structure is a marked syntactic device in our corpus-data. The sentences below occur succeeding sentence (1) above. The adverbs euphemize the speaker's connotation, as in:

(2) It [VP [Adverb (adv) really] made a difference to me ...]

(3) When I [VP was [Adv actually] there in Washington ...]

The position of the two Adverbs occurrence inside their VP varies. The adverb [really] in sentence (2) above precedes the HV [made] whereas the adverb [actually] follows HV [was] in (3) above.

More adverbs are also found to penetrate into the infinitival VP, as in the two examples below:

(4) I had the opportunity [InfVP to [Adv actually] speak] to some of the families ...]

(5) I began [InfVP to [Adv really] understand and appreciate] the enormity of the tragedy ...]

The HVs in (4) and (5) are [had] and [began] respectively where both are followed by infinitival phrases. The adverb [actually] is preceded by the infinitive particle [to] and is followed by the infinitival verb [speak]. Example (5) contains the two successive infinitival coordinated verbs [understand and appreciate] following the adverb modifier [really]. The frequency of the adverbs inside the VP in our data is 41 usages that is equivalent to $11.2 \%$ of the total verb structure devices as occurring in the corpus-data under scrutiny.

Thirdly, the lexicalization of the HV is also present in the data, as in:

(6) We all have been [HV glued] to our televisions [InfVP to comprehend ...]

The above example contains the lexicalized HV square bracketed; namely: [glued]. The infinitival verb is also square bracketed as [to comprehend]. Another lexicalized verb, to mention but one more example, in the data is [HV orphaned], and the frequency is found to be sixteen instances. This is equivalent to $4.3 \%$.

Fourthly, the VP-structure device of coordinating two VPs is also used in the data, and participates in creating 
euphemism. The following is a coordination of the two verbs in the two coordinated sentences:

(7) I [HV went] to New York and ... [HV visited] some of the families ...

Such coordination co-occurs to achieve euphemism at its best. This device forms $17.7 \%$ of the sixty five frequencies.

Fifthly, transitive dynamic HVs are found to occur denoting abstract and physical activities. They are basically loaded verbs and are pompous to help create inflated language. They carry power to convey carefully the intended concept of the speaker. Some extracted examples are as follows:

(8) feel, heard, believe, look, etc.

(9) talk, work, visit, understand, impose, aspire, achieve, express, etc.

HVs in (8) above refer to senses and those in (9) denote abstract and physical dynamism. They constitute $22.8 \%$ for the frequency of 84 occurrences.

Sixthly, passivisation is a significant verbal device to denote euphemism and is found as our last device to occur in the data. The following is one example extracted from the data:

(10) ... as one model that [VP needs [to be replicated] ...

The passivised structure is square bracketed as [to be replicated]. This device constitutes $14.6 \%$ for the 54 frequencies.

The following graph is a visual presentation summary of the six verbal devices as found in our data used for euphemizing the style. The graph presents both the frequency and the corresponding percentage for each verbal device presented in minimal to maximal order.

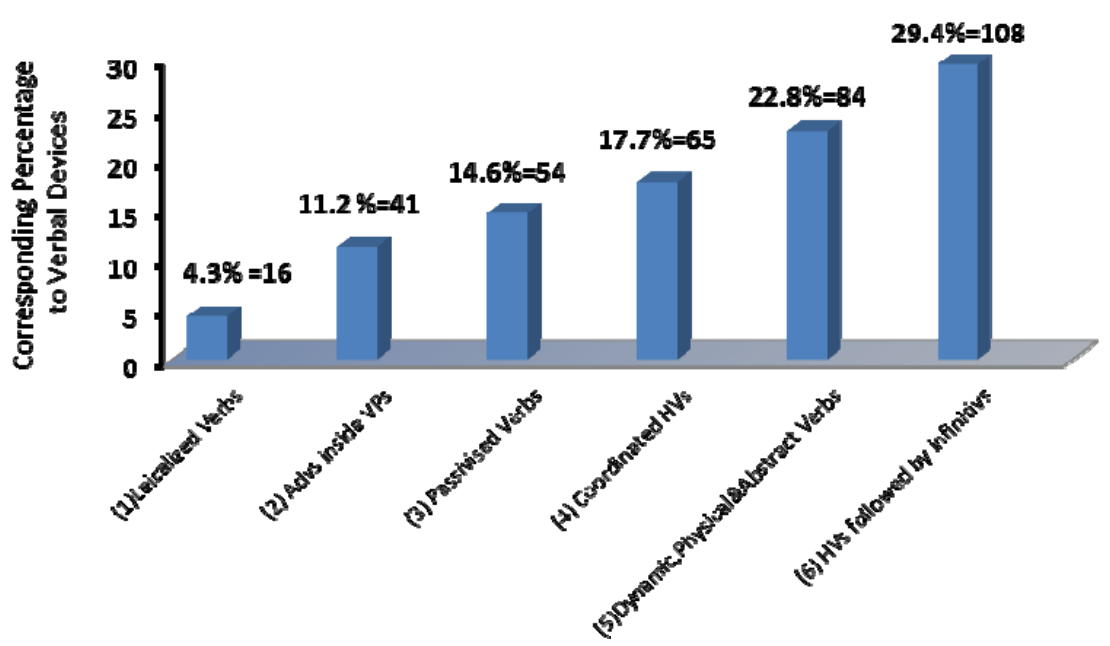

Graph 2. Six verb-structure devices: percentages and their frequencies

The total frequency of the verbal devices counts as 368 where the highest device is the infinitives which follow HV. This device seems to play the strongest role in euphemizing the style, where the lexicalization of the HV is the least to occur with only $4.3 \%$ of the total verbal devices. The power loaded verbs extend to apply their denotative effect on their arguments and they score $22.8 \%$ as the second highest. The third highest is the coordinated verbs $(17.7 \%)$, then the passivised verbs (14.6\%) followed by the device of adverbs inside their VPs $(11.2 \%)$ and the difference in their percentages is relatively not significant.

\subsubsection{The X-phemism Devices of Verbs Classification}

The structure technique of the verb and its VP are examined in this sub-section from the view of euphemism types within X-phemism. The sample data is analyzed for illustrations of the most dominant techniques of the $\mathrm{X}$-phemism used. The setting in this type of persuasive contextual style involves social, cultural and political issues. The analysis cites the most prominently occurring verb examples that are extracted from the corpus-data under scrutiny for ease of reference. 
It is worth mentioning that dysphemism does not exist in this corpus-data because of the nature of the context of the conversation which aims at a euphemized context of situation. Only two types of euphemisms are triggered within the verb structure. The first one is Jargon, including its sub-types of technical terms and emotive loaded verbs, and the second type is inflated pompous verbs, including its sub-types of description verbs and circumlocution verbs, (see Figure 1 above for type of X-phemism).

Type one: Jargon which relates to ideas discussed between members of the same group, as is the context of situation in our data. Only two sub-types are traced in the data; namely: technical terms and emotive verbs including pure verbs with positive and sneer verbs with negative connotations.

Technical terms as the first sub-type carry new ideological concepts. In our data, some extracted verbs that fall under analysis are:

(11) ... have been [HV orphaned]...

(12) We have [InfVP to voice] their concern.

(13) We all have been [HV glued] to our televisions ...

The terms are technically used to express a shared jargon between the user-candidate and the interviewer-listener/reader to express the devastating situations. The resulting solemn situation euphemizes the contexts where [orphaned] in (11) reflects the shared suffering by the speaker and [glued] in (13) expresses the peoples' true feeling reflected by the shocking news. Number (13) above has: [to voice] which expresses a call to make the voice of such people loud enough to be heard. The frequency of these verbs counts to seventy two which are $19.6 \%$ of the total X-phemism devices.

The second sub-type of Jargon is found in emotive loaded verbs of either purr or sneer verbs. Purr verbs involve positive connotations where they are found to occur more frequently than sneer verbs of the negative connotations. The following are some extracted examples:

(14) We really [VP began [InfVP to appreciate]] ...

(15) They [VP aspire [InfVP to achieve]] ...

(16) I [VP like [InfVP to commend]] you ...

The rich (or complex) structured VPs which involve HV followed by infinitives in the above three examples; namely: (14), (15), and (16) are only few extracts where loaded purr verbs are created. The percentage of the positive connotation purr verbs is $24.2 \%$ for the frequency of eighty-nine verbs. The negative loaded sneer verbs are fewer, as in:

(17) People [VP feel [Adv unfairly] treated] ...

(18) They [VP are not hated] by the rest of the world

(19) Honor-Killings [VP is not [HV1 condemned] or [HV2 accepted]] in Jordan...

Even though the contexts of the three above examples (17), (18), and (19), are about negative attitudes, they are still euphemized explicitly and implicitly. The structure is reflected explicitly in that (17) has the inserted Adverb inside the VP; the HV [hated] is negated in (18), and two coordinated HVs are also negated [condemned] and [accepted] in (19) above.

Type Two: Inflated Language which is triggered in our data. This type is also named 'pompous', 'loaded' or 'roundabout' language, (Allan and Bourdieu, 1981; Bolinger, 1980; Burridge, 1991; Gladney and Rittenberg, 2005; Holder, 2003; McGlone and Pfiester, 2006; and Rowson, 1995). Verbs and VPs are found to have a marked role to create a euphemized style using the two sub-types of this type; namely: description verbs, and in directional circumlocution verbs. This pompous style is used to paraphrase and euphemize what is objectionable or rejected.

The first sub-type of inflated language is description verbs. This sub-type occurs in a limited number in our data of only five frequencies. The following is one extracted example:

(20) ... about [VP trying [InfVP to [purify] our soul ...

The connotation here is implied in the individual choice in believing that the soul is 'contaminated' and requires 'purification'. The main idea is paraphrased by using the descriptive verb which is square bracketed: [purify], in (20) above. The verb is an indication of the duty of the person to practice his/her values. The preceding verb [trying] euphemizes the pompous verb of [purify].

The second sub-type of inflated language is the roundabout or circumlocution verbs. They are also called the 
indirection expressions. Verbs in our data are used to paraphrase certain concepts, and so euphemism occurs. Below are few extracted examples of these indirection expressions, or circumlocution verbs as follows:

(21) We've been [HV struggling] with what [SubV happened] ...

(22) ... [HV trying [InfVP to comprehend]] ...

(23) ... [HV trying [InfVP to make] sense of it.

The bracketed verbs above indicate the occurrence of HVs [struggling] in (21), and [trying] repeated in both (22) and (23) above. The stressful topic requires the speaker-candidate to follow the HVs with the subordinate verb [happened] in (21), and the InfVPs [to comprehend] and [to make] in (22) and (23) respectively. The speaker's aim is to confirm to the hearer that "we", (as in 21 above), also have been victimized by the event, which is expressed as "... what [happened]" as a roundabout expression. Similar circumlocutions are used in (22) and (23) to achieve euphemism. This sub-device has the highest frequency of fifty-four, which is $41.8 \%$ of euphemism devices in the scrutinized data.

Graph (3) below summarizes X-phemism types and sub-types with the focus on verbs as the tools of these devices. Frequency and percentage of verbs loaded with power as manifested in our corpus-data are presented on the graph below.

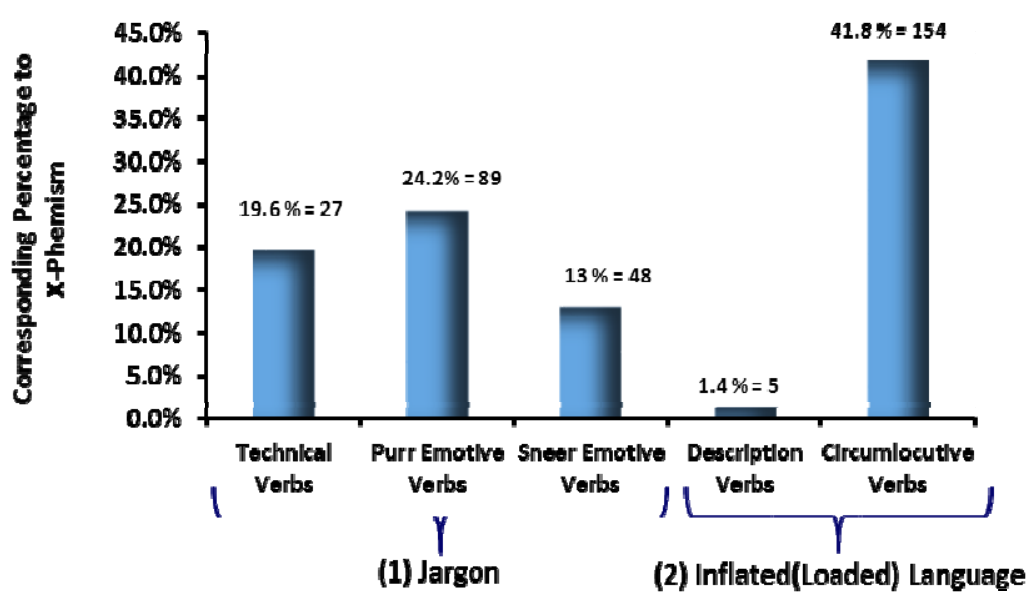

Graph 3. Euphemism Verb-devices: percentages and their frequencies

The above-graph summarizes the calculation of the number and its corresponding percentage for each verb device for the 368 verbs triggered in our corpus-data. The graph indicates that the device of circumlocution of the inflated language is a significant euphemistic technique. It has the highest frequency of 154 verbs with the corresponding percentage of $41.8 \%$ which is the highest. Similar conclusions are expressed in previous researches of different data-context, (Khatabi, 2009, p. 114).

The second sub-type of loaded language device is contrary to the above in having the lowest frequency of only five verbs. It corresponds to $1.4 \%$ which is an insignificant device for euphemism in our data. Purr verbs of positive emotion as one sub-device of Jargon shows the second highest technique in our data of $24.2 \%$ of the 89 frequency verbs.

The device of technical terms within Jargon is the third highest of $19.6 \%$ that is seventy-two verb-frequency. Finally, the second lowest technique is sneer verbs with negative connotation in Jargon. Their frequency is forty-eight verbs and the corresponding percentage is $13 \%$. The conclusion is expected in the context of our data which contains an overall euphemized style.

\section{Conclusions}

The context of the selected data for this study involves a number of issues of social, cultural, ideological and political concerns. Through the process of analysis, the discussion has justified the major claim in this paper. It is that the MV inside its VP is a powerful word loaded by its syntactic role through which the speaker's desire of doublespeak within X-phemism is achieved. The verbal devices form $29 \%$ among other structural devices, as 
indicated in graph (1) above.

Six types of verbal structures have been manifested in the corpus-data as follows from highest to lowest: verb infinitives following HV (29.4\%); dynamic abstract and physical HVs (22.8\%); coordinated HVs (14.5); passivised verbs (14.6\%); adverbs inside VPs (11.2\%); and lexicalized verbs (4.5). The results are visually presented in graph (2) above.

The verbs and their verbal components have been classified in order to capture the involved X-phemism techniques in these verbal devices. The conclusion manifests a total of five types and sub-types of euphemism as follows from highest to lowest: circumlocution indirection verbs (41.8\%); purr emotive verbs (24.2\%); technical verbs (19.6\%); sneer emotive verbs (13\%); and finally description verbs (1.4\%). Graph (3) above summarizes the frequency and the corresponding percentage of the euphemism devices which have been triggered in the corpus-data.

The most desirable verbal structure for euphemism is the infinitives following MVs in circumlocution of the roundabout language. This structural device tends to play a marked role in euphemizing the style. However, the lowest structural device is the lexicalized verbs used in the description euphemistic type of inflated language because it is the most explicit type, (see graphs 2 and 3 above).

\section{References}

Al-Barakati, M. (2009). Translating Euphemism from Arabic into English. PhD Thesis, Leeds University, UK.

Al-Hamad, M. O., \& Salman, A. M. (2013). The translatability of euphemism in the holy Qur'an.

Allan, K. (2009). The connotations of English Colour Terms: Colour- Based X-phemism. Journal of Pragmatics, 41(3), 626-637. http://dx.doi.org/10.1016/j.pragma.2008.06.004

Allan, K., \& Kate, B. (1991). Euphemism and Dysphemism: Language used as Shield and Weapon. Oxford: Oxford University Press.

Allan, K., \& Kate, B. (2006). Forbidden Words: Taboo and Censoring of Language. Cambridge: Cambridge University Press. http://dx.doi.org/10.1017/CBO9780511617881

Aunk, R. (2009). Doublespeak in Black and White. New York: Writers Club Press.

Bakhtiar, M. (2012). Communicative Functions of Euphemism in Persian. The Journal in International Social research, 5(20), 7-12.

Bolinger, D. (1980). Language the Loaded Weapon: The Use and Abuse of Language Today. London: Longman.

Bourdieu, P. (1981). Language and Symbolic Power. Cambridge: Polity Press.

Chomsky, N. (2000). Minimalist Inquiries: The Framework. In R., Martin, D. Michael, \& J. Uriajereka (Eds.), Step by Step: Essays on Minimalist Syntax in Honor of Howard Lasnik (pp. 89-155). Cambridge, Mass. MIT Press.

Enright, D. J. (1985). Fair of Speech: The Uses of Euphemism. Oxford: Oxford University Press.

Farghal, M. (1995). Euphemism in Arabic: A Gricean Interpretation. Anthropological Linguistics, 37(3), 366-378.

Farghal, M. (2005). Arabic Euphemism in English Translation. IJAES, 6, 57-70.

Fernandez, E. C.(2008). Sex Related Euphemism and Dysphemism: An Analysis in Terms of Conceptual Metaphor Theory. Atlantis Journal of the Spanish Association of Anglo-American Studies, 30(2), 95-110.

Galal, M. M. (2014). Death euphemism in English and Arabic: A Conceptual metaphorization approach. International Journal of Linguistics, 6(1), 153. http://dx.doi.org/10.5296/ijl.v6i1.4514

Gladney, G. A., \& Terri, L. R. (2005). Euphemistic Text Affects Attitudes, Behavior. In Newspaper Journal Find Articles, 1-10.

Grice, P. (1989). Studies in the Way of Words. Cambridge, Mass.Harvard University Press.

Holder,. W. (2003). How not to Say What You Mean: A Dictionary of Euphemism. Oxford: Oxford University Press.

Khanfar, M. (2012). Euphemism in Arabic Typology and formation. Journal of the college of Arts, 61, 1-34.

Khatabi, A. M. A. (2009). An Analysis of the Role of X-Phemism as an Aspect of Doublespeak. M.A Thesis, Makkah: Umm Al-Qura University, VDM Publishing House, Amazon. 
Kick, R. (2001). You Are Being Lied To. New York: The Disinformation Company Limited.

Lutz, W. (1989). Beyond Nineteen- Eighty Four: Doublespeak in a Post-Orwellian Age. The New Illinois NCTE.

Martin, R., David, M., \& Juan, U. (2002). (eds.). Step by Step: Essays on Minimalist Syntax in Honor of Howard Lasnik. Cambridge, Mass.: MIT Press.

Mazid, Bahaa-Eddin M. (2003). Sharp Wits and Fine Phrases: Euphemism and Dysphemism in War on Iraq Discourse. Cairo Studies in English, 43-84.

Mazid, Bahaa-Eddin, M. (2004). Euphemism and Dysphemism in the War-on-Iraq Discourse. IJAES, 5, 171-188.

Mazid, Bahaa-Eddin M. (2007a). Presupposition and Strategic Functions in Bush's September, 20th, 2001 Speech. Journal of Language and Politics, 6(3), 347-371.

Mazid, Bahaa-Eddin M. (2007b). Politics of Translation: Power, Culture, Ideology and X- Phemism in Translation Between Arabic and English. In Linco Europa.

Mazid, Bahaa-Eddin M. (2008). Cowboy and Misanthrope: A Critical Discourse Analysis of Bush and Bin Laden Cartoons. Discourse Communication, 4(2), 433-457. http://dx.doi.org/10.1177/1750481308095939

Mazid, Bahaa-Eddin M. (2009). Date-Palms, Language and the Power of Knowledge: An Analysis of a Fable from Kalila and Dimna. Journal of Pragmatics, 41(12), 2515-2534. http://dx.doi.org/10.1016/j.pragma.2009.04.007

McGlone, Matthew, S., Beck, G., \& Abigail, P. (2006). Contamination and Camouflage in Euphemism. Communication Monographs, 73, 261-282. http://dx.doi.org/10.1080/03637750600794296

Orwell, G. (1950). Nineteen-Eighty Four. London: Penguin.

Ouhalla, J. (2002). Introduction to Transformational Grammar: From Principles and Parameters to Minimalism. London: Arnold.

Qadhi, N. (2009). A Sociolinguistic Comparison of Euphemisms in English and Arabic. Journal of King Saud University, Riyadh, Language and Translation, 21, 13-22.

Rawson, H. (1995). Dictionary of Euphemism and Other Doublespeak (2nd ed.). New Jersey: Castle Books.

Reznikove, A. (2001). George Orwell's Theory of Language. USA: Anderi Reznikove.

Van Dijik, T. A. (2007). Critical Discourse Analysis. In Discourse and Power: Contribution to Critical Discourse Studies (pp. 108-125), Hound mills: Palgrave, McMillan.

Van Dijk, T. A. (2010). Discourse and Context: A Sociocognitive Approach. Cambridge: Cambridge University Press.

Wood, R. (2008). Kalila and Dimna, Fables of Friendship and Betrayal, Introduction by Doris Lessing, Postscript by Dr Christine van Ruymbeke, London: Saqi Books.

\section{Copyrights}

Copyright for this article is retained by the author(s), with first publication rights granted to the journal.

This is an open-access article distributed under the terms and conditions of the Creative Commons Attribution license (http://creativecommons.org/licenses/by/3.0/). 